\title{
Understanding the Effect of Severity Factor of Prehydrolysis on Dissolving Pulp Production Using Prehydrolysis Kraft Pulping and Elemental Chlorine-free Bleaching Sequence
}

\author{
Wei Wei, ${ }^{\text {a }}$ Zhongjian Tian, ${ }^{\mathrm{a}}$ Xingxiang Ji, ${ }^{\mathrm{a}, \mathrm{b}, *}$ Qiang Wang, ${ }^{\mathrm{a}}$ Jiachuan Chen, ${ }^{\mathrm{a}, *}$ Gecang \\ Zhang, ${ }^{b}$ and Lucian A. Lucia ${ }^{\mathrm{a}, \mathrm{c}}$
}

\begin{abstract}
Prehydrolysis kraft pulping is an effective approach to produce dissolving pulp, which can be used for viscose application. The prehydrolysis process using hot liquid water could remove hemicellulose and loosen the compact cell wall, thus facilitating subsequent pulping and bleaching processes. In this study, the composite severity factor (CSF) was used to reveal the intensity of prehydrolysis treatment and its effect on the pulping and bleaching process by combining the temperature, time, and $\mathrm{pH}$ variables. Results showed that the optimum CSF was 6.61 , which produced a pulp with $\alpha$-cellulose of $92.3 \%$, degree of polymerization (DP) of 1081 , brightness of $85.1 \%$ ISO, and Kappa number of 0.61 . In addition, the fiber quality, crystalline structure, and microstructure of pulps were characterized by FQA (fiber quality analysis), XRD (X-ray diffraction), and SEM (scanning electron microscopy).
\end{abstract}

Keywords: Liquid hot water (LHW) pretreatment; Composite severity factor (CSF); Kraft cooking; Elemental chlorine-free (ECF) bleaching; Cellulose crystallinity

Contact information: a: State Key Laboratory of Bio-based Materials and Green Papermaking, Qilu University of Technology (Shandong Academy of Sciences), 3501 Daxue Road, 250353, Jinan, China; b: Chenming Group, 2199 Nongsheng East Street, Shouguang, Shandong Province; c: North Carolina State University, Department of Forest Biomaterials, Raleigh, NC 29675-8005, USA;

*Corresponding authors: xxjt78@163.com; chenjc@qlu.edu.cn

\section{INTRODUCTION}

As the economy and society have developed, there has been a depletion of petrochemical resources that has resulted in an energy crisis, which has received extensive worldwide attention (Yang et al. 2011). Biomass resources, an energy source with its recyclability and environmental benefits, are being taken seriously as alternatives to petrochemical resources. Biomass resources are mainly composed of cellulose, hemicelluloses, and lignin with trace amounts of ash. The pulp and paper industry is a large consumer of biomass resources; the introduction of biomass refining will become a necessity for its development (Francis et al. 2006; Tschirner et al. 2010). Fast-growing aspen was selected for use in the present study because it is widely used to manufacture dissolving pulps in North China by the prehydrolysis treatment and kraft pulping process (Wang et al. 2015).

In the process of biomass refining, the selective separation of hemicelluloses from other biomass constituents is an important research topic and is a key stage in the production of dissolving pulps. Thus far, there are many methods for separating hemicelluloses from wood chips, which include dilute acid prehydrolysis (Al-Dajani et al. 
2009) and alkali pre-extraction (Walton et al. 2010), hot water extraction (HWE) (Borrega et al. 2013, Leppänen et al. 2011), steam treatment (STS) (Hinck et al. 1985), organosolv pretreatment, and ionic liquid pretreatment (Le et al. 2019). Among these processes, hot water prehydrolysis is an effective method for separating hemicelluloses. The process is conducted under high temperature whereby acetic acid is generated, as the hemicelluloses are deacetylated; the acidic conditions hydrolyze the bonds between the hemicelluloses and the lignin structures, as well as other components, in the wood chip. The hemicelluloses' polymer chains are further degraded to form oligosaccharides and monosaccharides (Duarte et al. 2011). With the formation and dissolution of acids, the $\mathrm{pH}$ of the prehydrolysate continues to decrease, which leads to further dissolution of the hemicelluloses (Gütsch et al. 2012; Weinwurm et al. 2017). The liquid hot water (LHW) prehydrolysis has low energy consumption, low pollution load, and low cost, as well as high hydrolysis and recovery rates of the hemicelluloses (Narron et al. 2017). The removal of hemicelluloses by hydrothermal pretreatment will have an impact on the cellulose and the lignin in the pretreated wood chips, which will affect their subsequent pulping and bleaching. In order to evaluate the severity of prehydrolysis stage, the combined severity factor (CSF) was selected in this study. In the literature, CSF has been employed to balance the lignin breakage and glucose enzymatic saccharification (Yuan et al. 2019). Liu et al. (2015) studied the difference performance of resulted pulp after varied severity of hot water extraction. Shi et al. (2019) studied the sedimentary substance formed on the wood chips surface at various severity of hot water prehydrolysis.

Elemental chlorine-free (ECF) bleaching of chemical pulps is the main technology used in the pulp and paper industry (Lin et al. 2018). Yao et al. (2017) found that removal of the hemicelluloses could inhibit the formation of chlorinated organics and chlorophenols, and most of the macromolecules with aromatic structure were degraded into chain macromolecules and small organochlorides. Prehydrolysis is an effective treatment method to remove hemicelluloses.

In this study, the extended combined severity factor (CSF) was used to quantify the severity of the LHW prehydrolysis treatment to determine the effect of the treatment on kraft pulping and D(EP)P pulp bleaching. Through the analyses of pulp brightness, $\alpha$ cellulose content, degree of polymerization (DP), and Kappa number, the most suitable CSF condition for utilizing biomass resources was determined.

\section{EXPERIMENTAL}

\section{Materials}

Fast-growing aspen chips, which were composed of $43.7 \%$ cellulose, $28.0 \%$ hemicelluloses, 23.2\% lignin, 3.25\% other components (extractives and ash), were kindly provided by Shan Dong Sun Paper Industry Joint Stock Co., Ltd. (Jining, China). Sodium hydroxide, sodium sulfide, and hydrogen peroxide were purchased from Tianjin Damao Chemical Reagent Factory (Tianjing, China). Chlorine dioxide solutions were obtained from Shandong Shanda Huart Environmental Protection Engineering Co., Ltd. (Jinan, China).

\section{LHW Prehydrolysis Treatment}

The composition analysis of the wood chips was determined according to the method from the National Renewable Energy Laboratory (Sluiter et al. 2012). The 2-L 
stainless steel pressure reactor (model GKCF-2; Yingyu High Technique Instrument Factory, Gongyi, China) was filled with $250 \mathrm{~g}$ wood chips and $1.5 \mathrm{~L}$ deionized water. The reactions were conducted at a temperature between $100{ }^{\circ} \mathrm{C}$ to $200{ }^{\circ} \mathrm{C}$ (at $20^{\circ} \mathrm{C}$ increments) for $60 \mathrm{~min}$ using a stirring speed of $150 \mathrm{rpm}$. After each reaction, the prehydrolysis liquor and solids in reactor were separated by filtration through a gauze filter $(0.074 \mathrm{~mm})$; the obtained solids were air-dried.

\section{Kraft Cooking After LHW Prehydrolysis}

Air-dried hydrolysis wood chips (100 g) were cooked at $165^{\circ} \mathrm{C}$ for $90 \mathrm{~min}$ using a 1-L stainless steel pressure reactor (model 2615; Kumagai Riki Kogyo Co., Ltd., Tokyo, Japan). The kraft cooking liquor had an active alkali (as equivalent $\mathrm{Na}_{2} \mathrm{O}$ ) of $18 \%$ and a sulfidity of $20 \%$; a $4: 1$ cooking liquor-to-wood ratio $(\mathrm{v} / \mathrm{w})$ was used. When the pulping reaction finished, the pulp was washed, screened, and air-dried for later use.

\section{Elemental Chlorine-free (ECF) Bleaching}

The conditions used for each of the bleaching stages in the ECF bleach sequence were as follows:

\section{Chlorine dioxide delignification (D stage)}

A pulp consistency (PC) of $10 \%, \mathrm{NaOH}$ dosage of $0.4 \%$ on pulp, reaction temperature of $70{ }^{\circ} \mathrm{C}$ for $90 \mathrm{~min}$, and chlorine dioxide $\left(\mathrm{ClO}_{2}\right)$ dosage of $0.7 \%$ on pulp were used (Rizaluddin et al. 2015).

\section{Alkaline extraction reinforced with hydrogen peroxide (EP) stage}

A PC of $10 \%, \mathrm{H}_{2} \mathrm{O}_{2}$ dosage of $0.5 \%$ on pulp, $\mathrm{NaOH}$ dosage of $2.0 \%$ on pulp, reaction temperature and time of $70{ }^{\circ} \mathrm{C}$ for $60 \mathrm{~min}$, diethylenetriaminepentaacetic acid (DTPA) dosage of $0.5 \%$ on pulp, and $\mathrm{MgSO}_{4}$ dosage of $0.1 \%$ on pulp were used.

\section{Hydrogen peroxide brightening ( $P$ stage)}

A PC of $10 \%, \mathrm{Na}_{2} \mathrm{SiO}_{3}$ dosage of $0.5 \%$ on pulp, $\mathrm{H}_{2} \mathrm{O}_{2}$ dosage of $1.5 \%$ on pulp, pH of 11.0 via addition of a small amount of $\mathrm{NaOH}$ to the pulp suspension, reaction temperature and time of $90{ }^{\circ} \mathrm{C}$ and $90 \mathrm{~min}$, DTPA dosage of $0.5 \%$ on pulp, and $\mathrm{MgSO}_{4}$ dosage of $0.1 \%$ on pulp were used.

\section{Pulp Testing}

Kappa number and $\alpha$-cellulose content of the pulps were determined according to the TAPPI T236 om-06 (2006) and TAPPI T203 cm-09 (2009) standards, respectively.

The pulp viscosity was measured according to the TAPPI T 230 om-13 (2013). To facilitate the analysis of experimental results, the pulp viscosity ( $\mathrm{mPa} \cdot \mathrm{s})$ was measured and converted to degree of polymerization (DP) according to Eq. 1 (Shi et al. 2015),

$$
D P^{0.905}=0.75 \mathrm{~V}
$$

where, the $V$ is the pulp viscosity $(\mathrm{mPa} \cdot \mathrm{s})$.

The brightness of the pulp was measured according to TAPPI T452 om-92 (1992) standard using a digital color meter (model YQ-Z-48B; Hangzhou Lightcom Boko Automation Technology Co., Ltd., Hangzhou City, China). The length, width, and fines content of the fibers in the pulps were determined using an L\&W FS5 fiber quality analyzer (Lorentzen \& Wettre, Kista, Sweden). 
The XRD method was used to determine the crystallinity of the cellulose in the pulp before and after each treatment. X-ray diffraction data were obtained using a Rigaku D/Max 2500 VB2+/PC (Rigaku, Tokyo, Japan) and the samples were milled into powder form. A scanning angle range between $5^{\circ}$ to $40^{\circ}$ and a scanning speed of $2 \%$ min were used. With the XRD data collection, the cellulose I characteristic peak was near $2 \theta$ of $22.5^{\circ}$ ([002] lattice plane), whereas the amorphous cellulose characteristic peak was near $2 \theta$ of $18^{\circ}$. To calculate the crystallinity index $(\mathrm{CrI})$, the Origin 8.0 software (Rigaku, Tokyo, Japan) was used; the $C r I$ equation is as follows (Agarwal et al. 2017; Oliveira et al. 2017),

$$
C r I=\left(\left(I_{002}-I_{\mathrm{am}}\right) / \mathrm{I}_{002}\right) \times 100 \%
$$

where, $I_{002}$ is the XRD intensity at $22.5^{\circ}$ for crystalline cellulose and $I_{\mathrm{am}}$ is the XRD intensity at $18^{\circ}$ for amorphous cellulose.

Dry pulp samples from various prehydrolysis treatments were pasted onto sample tables with conductive adhesive for gold sputtering (SBC-12; KYKY Technology Co., Ltd., Beijing, China). The prepared samples were imaged using a scanning electron microscope (SEM) (model S-3400N; Hitachi, Tokyo, Japan).

\section{Composite Severity Factor (CSF) of LHW Prehydrolysis}

For LHW pretreatment, the two reaction parameters, time and temperature, can be classified as a single empirical variable. That is, the severity factor, which is generally defined as Eq. 3 (Overend and Chornet 1987; Yuan et al. 2019),

$$
R_{0}=t \times \exp \left(\frac{T-100}{14.75}\right)
$$

where, $t$ is the prehydrolysis time ( $\min ), T$ is the prehydrolysis temperature $\left({ }^{\circ} \mathrm{C}\right)$, and 100 ${ }^{\circ} \mathrm{C}$ is the reference temperature. During the pretreatment process, acetic acid is released from the deacetylated hemicelluloses; the accumulation of acetic acid assists with acid hydrolysis of the hemicelluloses. When considering the effects of reaction temperature, time, and acid concentration on the hydrolysis of the hemicelluloses, a CSF was used (Chum et al. 1990). However, to compare various pretreatment severities, an extended CSF can be calculated (Pedersen and Meyer 2010) using Eq. 4:

$$
\mathrm{CSF}=\log R_{0}+|p \mathrm{H}-7|
$$

In this study, Eq. 4 was used to compare the severities of various prehydrolysis conditions and their effects on the resulting pulp properties. The specific pretreatment parameters of the wood chips (hydrolysis temperature, time, and $\mathrm{pH}$ ) and the calculated CSF values are listed in Table 1. It should be note that the $\mathrm{pH}$ was the final $\mathrm{pH}$ of PHL after prehydrolysis stage.

Table 1. Calculated CSF Values for Various Pretreatment Conditions

\begin{tabular}{|c|c|c|c|c|}
\hline Temperature $\left({ }^{\circ} \mathrm{C}\right)$ & Time $(\min )$ & $\mathrm{pH}$ & $R_{0}$ & $\mathrm{CSF}$ \\
\hline 100 & 60 & 4.29 & 60.00 & 4.49 \\
\hline 120 & 60 & 4.22 & 232.82 & 5.14 \\
\hline 140 & 60 & 4.14 & 903.44 & 5.81 \\
\hline 160 & 60 & 3.93 & 3505.68 & 6.61 \\
\hline 180 & 60 & 3.53 & $13,603.38$ & 7.60 \\
\hline 200 & 60 & 3.35 & $52,786.23$ & 8.37 \\
\hline
\end{tabular}




\section{RESULTS AND DISCUSSION}

\section{Effects of CSF on Wood Chips}

Prehydrolysis leads to the cleavage of the glycosidic bonds in the hemicelluloses and the dissolution of small amounts of lignin, which are transferred to the liquid hydrolysate; this results in changes to the solid wood chip (Li et al. 2017). After LHW prehydrolysis at different CSF values, the removal rates of the three constituents of poplar wood chips are shown in Fig. 1.

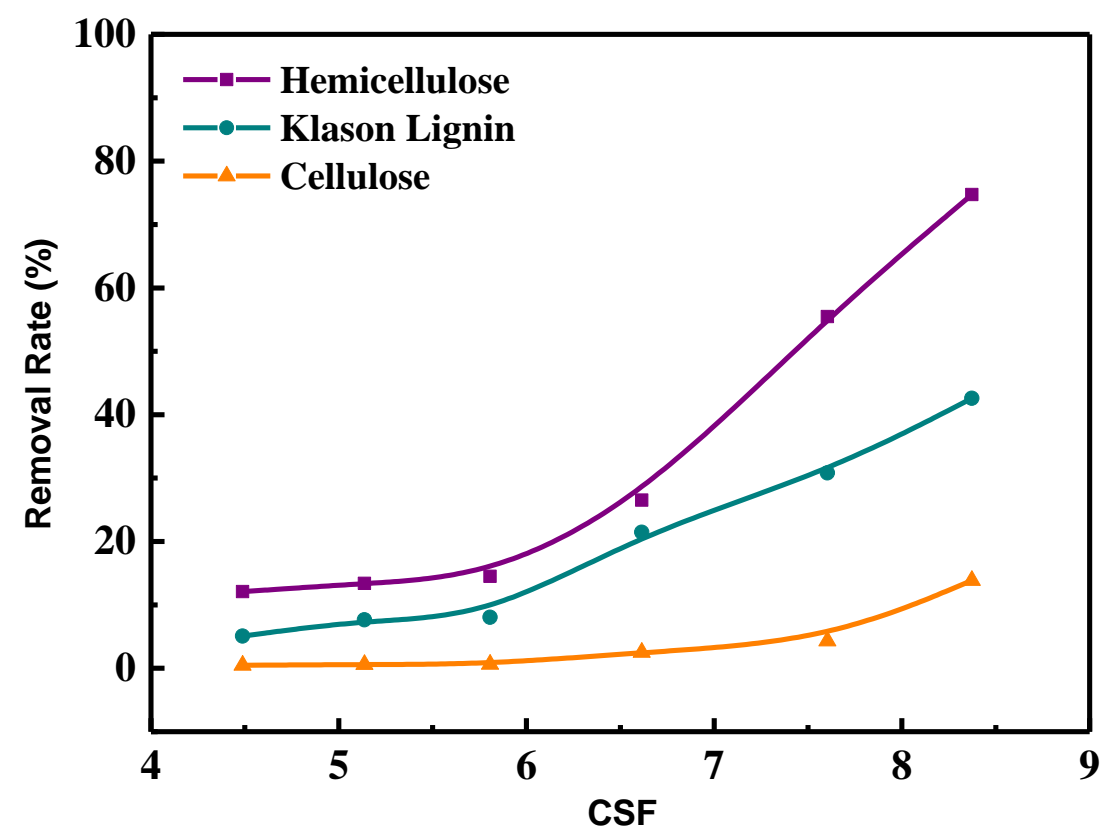

Fig. 1. The removal rate of lignin, hemicelluloses, and cellulose wood constituents

In Fig. 1, the removal extents of cellulose, hemicelluloses, and lignin increased as the CSF intensified from 4.49 to 8.37. The trend of the hemicellulose removal was the most obvious. It is worth noting that there was a cut-off point when the CSF was 5.81. When the CSF was within the range of 4.49 to 5.81 , the removal extents of the three components did not appreciably increase; within this range, the cellulose was essentially not removed, the lignin was slightly removed, and the hemicelluloses were much more removed. When the CSF was 4.49, the cellulose and lignin were effectively not removed. When the CSF was initially increased, the removal of the three components increased slowly; the removal extents of lignin and hemicelluloses appeared to reach an inflection point when the CSF was 5.81, and then they rapidly increased in a linear fashion, whereas the removal extent of cellulose reached an inflection point when the CSF was 6.61. When the CSF was in the range of 5.81 to 8.37 , all the three components were removed in large amounts.

\section{Effects of CSF on Kraft Pulping and D(EP)P Pulp Bleaching}

\section{Kraft pulping}

Due to the dissolution of the hemicelluloses, the porosity of the hydrolyzed wood chips increased, which resulted in the partial degradation of lignin and the cleavage of lignin-carbohydrate complexes (LCCs) (Sixta 2006). Generally speaking, the removal of hemicellulose increased to $74.3 \%$ as the CSF intensified to 8.37. Due to these changes to 
the wood chips, the prehydrolysis process will affect the lignin removal extent of wood chips during kraft pulping and $\mathrm{D}(\mathrm{EP}) \mathrm{P}$ pulp bleaching.

Table 2. Effects of CSF on Unbleached Kraft Pulp

\begin{tabular}{|c|c|c|c|c|c|c|}
\hline CSF & 4.49 & 5.14 & 5.81 & 6.61 & 7.6 & 8.37 \\
\hline Yield (\%) & 49.93 & 49.41 & 49.07 & 45.27 & 38.99 & 31.10 \\
\hline$\alpha$-cellulose (\%) & 82.92 & 83.86 & 84.56 & 86.65 & 88.29 & 89.84 \\
\hline Brightness (\% ISO) & 32.92 & 33.44 & 33.63 & 34.56 & 34.98 & 35.10 \\
\hline DP & 1304 & 1384 & 1380 & 1290 & 1258 & 1068 \\
\hline Kappa Number & 27.74 & 25.15 & 24.15 & 22.45 & 20.55 & 16.76 \\
\hline
\end{tabular}

Table 2 displays the effects of prehydrolysis CSF value on unbleached kraft pulp properties. From this table, it can be seen that different CSF values had an obvious effect on the properties of the kraft pulp. The yield, cellulose DP, and Kappa number decreased with the increase of CSF. At the same time, the brightness and $\alpha$-cellulose content showed an increasing trend. When the CSF was 5.81, it was a noteworthy cut-off point. When the CSF was less than 5.81, the yield was approximately $49 \%$, and the $\alpha$-cellulose content was less than $85 \%$; however, the brightness was relatively low, and the Kappa number was relatively high. When the CSF was greater than 5.81, the yield was observed to decrease to less than $45.5 \%$. In addition, the content of $\alpha$-cellulose increased to more than $86 \%$, the brightness obviously increased, and the DP and Kappa number obviously decreased.

As shown in Fig. 2, the length, width, and fines content of the pulp were altered when the CSF value continued to increase. Obvious changes occurred when the CSF reached 5.81. When the CSF was 5.81, the fiber length, width, and fines content noticeably decreased. When the CSF was less than 5.81, the fiber length and fiber width were higher. When the CSF was greater than 5.81, the fiber length and fiber width were smaller and tended to be stable (i.e., these parameters essentially did not change as the CSF value increased).

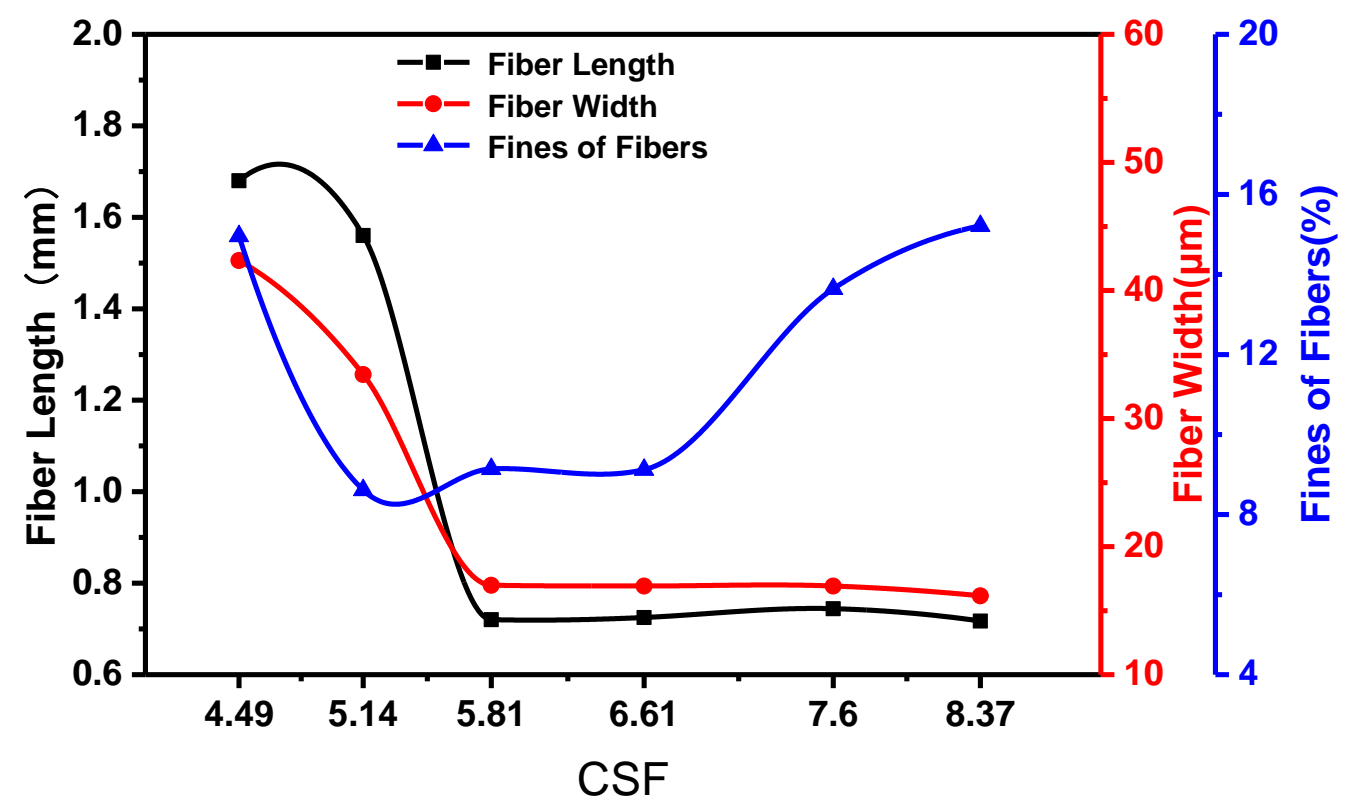

Fig. 2. Effects of CSF on unbleached kraft pulp fiber size 
The content of fines increased when the CSF increased above 6.61, and the fiber length and width were decreased with increasing CSF from 4.49 to 5.81. This was mainly because the contents of the hemicelluloses were high when the CSF value was low, which was not conducive to the penetration of the kraft cooking liquor; this resulted in insufficient cooking of the wood chips. When the CSF was too high, the hemicelluloses were mainly removed, and the cooking liquor was sufficiently contacted with the cellulose, which caused some of the long fibers to be degraded into short fibers (Duarte et al. 2011).

\section{Bleaching}

Table 3 shows the effect of different prehydrolysis CSF values on the ECF bleaching of the resulting kraft pulps. Due to the different CSF values, the degree of prehydrolysis was different, which led to differences in the type and quantity of lignin in the pulp after pulping. Hence, under the same bleaching treatment, the unbleached pulp bleached differently when different CSF values were used during the wood chip prehydrolysis.

Table 3. Effects of CSF on D(EP)P Pulp Properties

\begin{tabular}{|c|c|c|c|c|c|c|c|}
\hline $\begin{array}{c}\text { CSF } \\
\text { Process }\end{array}$ & & 4.49 & 5.14 & 5.81 & 6.61 & 7.60 & 8.37 \\
\hline \multirow{4}{*}{ D } & $\alpha$-cellulose (\%) & 84.70 & 86.67 & 87.96 & 90.18 & 92.86 & 91.85 \\
\cline { 2 - 8 } & Brightness (\% ISO) & 46.15 & 48.78 & 49.96 & 49.15 & 52.97 & 55.51 \\
\cline { 2 - 8 } & DP & 1213 & 1070 & 1105 & 1148 & 1051 & 999 \\
\cline { 2 - 8 } & Kappa No. & 9.39 & 8.42 & 7.64 & 6.84 & 5.97 & 5.07 \\
\hline \multirow{5}{*}{ D(EP) } & $\alpha$-cellulose (\%) & 85.86 & 87.30 & 87.17 & 91.95 & 93.10 & 93.29 \\
\cline { 2 - 8 } & Brightness (\% ISO) & 78.73 & 79.72 & 81.55 & 81.52 & 82.13 & 82.59 \\
\cline { 2 - 8 } & DP & 1137 & 1137 & 1134 & 1149 & 1036 & 968 \\
\cline { 2 - 8 } & Kappa No. & 1.32 & 1.21 & 0.71 & 0.84 & 0.51 & 0.32 \\
\hline \multirow{4}{*}{ D(EP)P } & $\alpha$-cellulose (\%) & 86.38 & 88.99 & 90.20 & 92.30 & 94.93 & 94.62 \\
\cline { 2 - 8 } & Brightness (\% ISO) & 84.16 & 84.38 & 84.96 & 85.18 & 88.44 & 89.18 \\
\cline { 2 - 8 } & DP & 997 & 1003 & 1020 & 1081 & 1010 & 807 \\
\cline { 2 - 8 } & Kappa No. & 1.13 & 0.89 & 0.91 & 0.62 & 0.56 & 0.25 \\
\cline { 2 - 8 } & Yield (\%) & 76.30 & 78.39 & 80.52 & 83.20 & 81.20 & 79.30 \\
\hline
\end{tabular}

After chlorine dioxide delignification, the Kappa number reduction of the unbleached pulp was between $66 \%$ and $70 \%$. When the CSF was 4.49 and 5.81, the Kappa number reduction was relatively low (approximately 66\%). However, when the CSF approached 6.61, the amount of delignification approached 69.6\%; delignification did not appreciably increase when the CSF was increased above 6.61. In this first stage of the bleach sequence, the chlorine dioxide mainly attacks the phenolic groups of the lignin, which degrades the lignin polymer into smaller fragments that are more soluble and extractable (Zhang et al. 2018). This action is the main reason for the decrease in the pulp's Kappa number. Hence, it is reasonable that an increase of prehydrolysis CSF value would improve the efficiency of the chlorine dioxide delignification stage.

After the chlorine dioxide delignification stage, alkaline extraction enhancement with hydrogen peroxide was used. After the first two bleaching stages, the unbleached pulp brightness was considerably changed. Generally speaking, the brightness after D(EP) was 
close to $80 \%$ ISO, with a maximum of $82 \%$ ISO being observed. When the CSF was 4.49 , the unbleached brightness increase was the highest, which was $139.2 \%$. Generally, the absolute percentage change in pulp brightness across the $D(E P)$ sequence decreased when the CSF was continuously increased. Pulp brightness did not greatly improve because chlorine dioxide treatment resulted in insoluble oxidized lignin with color substances; hence, the D stage did not improve pulp brightness. However, the alkali extraction stage reacted well with the modified residual lignin to ionize its organic acid groups, which made the lignin more soluble in alkali solutions. Hence, the brightness was considerably improved during the second bleaching stage (Teleman et al. 2001).

After the $\mathrm{D}(\mathrm{EP}) \mathrm{P}$ bleach sequence, the final pulp properties were evaluated and are presented in Table 2 . The pulp purity ( $\alpha$-cellulose) reached $94.6 \%$, which is close to dissolving pulps made from hardwoods (Jahan et al. 2016). The purpose of the final bleaching treatment is mainly to increase the $\alpha$-cellulose content of the pulp. The $\alpha$ cellulose is alkali-insoluble due to its high crystallinity, has a stable performance, is conducive to the further utilization of cellulose, and it is also an important quality evaluation of dissolved pulp standards. Compared with Table 2, it can be clearly seen that when the CSF was 7.6, the $\alpha$-cellulose content reached its highest value, which increased $7.52 \%$ over the unbleached pulp. The cellulose DP rapidly decreased when the CSF was 5.14 with a $27.5 \%$ reduction across the $\mathrm{D}(\mathrm{EP}) \mathrm{P}$ sequence.

In general, the D stage considerably reduced the pulp's Kappa number, the D(EP) sequence mainly affected the pulp's brightness, and the $\mathrm{D}(\mathrm{EP}) \mathrm{P}$ sequence affected the pulp's $\alpha$-cellulose content. Therefore, a reasonable increase in the prehydrolysis CSF is conducive to bleaching. In particular, the performance of pulp reached a critical cut-off when the CSF approached 5.81. For ECF bleaching of kraft poplar pulp, a CSF value of 6.61 is the most conducive condition to produce bleached dissolving pulp; that is, a pulp with a brightness of $85.1 \%$ ISO, an $\alpha$-cellulose content of $92.3 \%$, a cellulose DP of 1081 , a Kappa number of 0.62 , and a bleached yield of $83.2 \%$.

Figure 3 shows the effect of prehydrolysis CSF value on pulp fiber size after each bleaching stage. After the D stage, the length, and width of the fibers remained relatively unchanged; this indicated that the CSF value had little influence on the length and width of the pulp fibers after the D stage. After bleaching, the number of fines in the pulp increased as the CSF increased. When compared to the original pulp, when the CSF was 5.14 , the prehydrolysis conditions resulted in fiber length and width reduction of $75.4 \%$ and $51.5 \%$, respectively. At a CSF value of 6.61 , the fiber length and width reductions were $4.4 \%$ and $9.6 \%$, respectively.

It can be seen from Fig. 3 that the length and width of the fibers after $D(E P)$ bleaching tended to decrease as CSF increased; nonetheless, these differences were small. However, the changes in the amounts of fines were relatively high, which showed a decreasing trend first and then increased. When the CSF was 7.6, the level of the fine reached a maximum value of $15.4 \%$.

It can be clearly seen from Fig. 3 that both fiber length and width generally decreased as CSF increased, but the trends slowly changed. In contrast, the content of fines changed most notably. When the CSF was greater than 6.61, the content of fines rapidly increased. This observation indicated that high CSF could lead to the shortening of long fibers. 


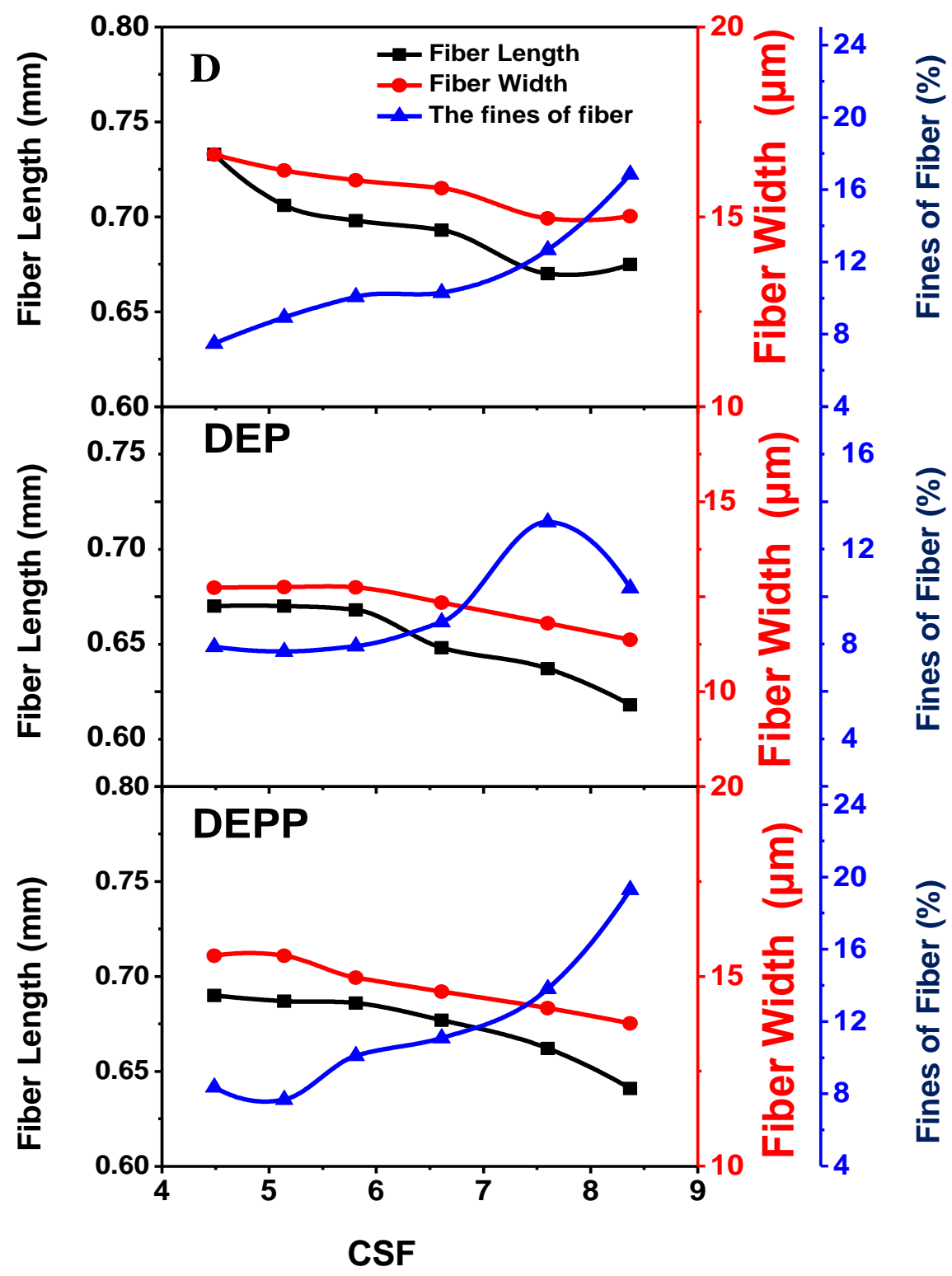

Fig. 3. Effects of CSF on D(EP)P fiber size

Other evidence supporting this explanation was the observed decrease in cellulose DP, fiber length, and width. This may have been because when the CSF value was relatively small, the content of lignin in the pulp was relatively high, and the bleaching oxidants mainly reacted with lignin and hemicelluloses attached to the surfaces of the cellulose fibers. This resulted in minimum cellulose damage and no effect on fiber length. As the prehydrolysis CSF is increased, there is less lignin attached to the surfaces of the cellulose fibers (Rizaluddin et al. 2015). The bleaching oxidants can directly react with the cellulose, which degrades the cellulose and shortens the fibers that result in a large number 
of fines being generated. These findings are in agreement with the observed changes to cellulose DP values during bleaching.

\section{Microstructure Analysis of Fibers}

Figure 4 shows the XRD patterns from three different CSF pulps after bleaching. It can be seen that higher CSF resulted lower cellulose crystallinity due to the reduction of amorphous region. The positions of the diffraction peaks of the pulps made with different CSF values were similar. A strong diffraction peak at $22.5^{\circ}$ had relatively small changes, which indicated that the crystallinities were different for different CSF values. The calculated crystallinity was $71.2 \%, 75.4 \%$, and $79.9 \%$ for CSF values of $4.49,6.61$, and 8.37 , respectively.
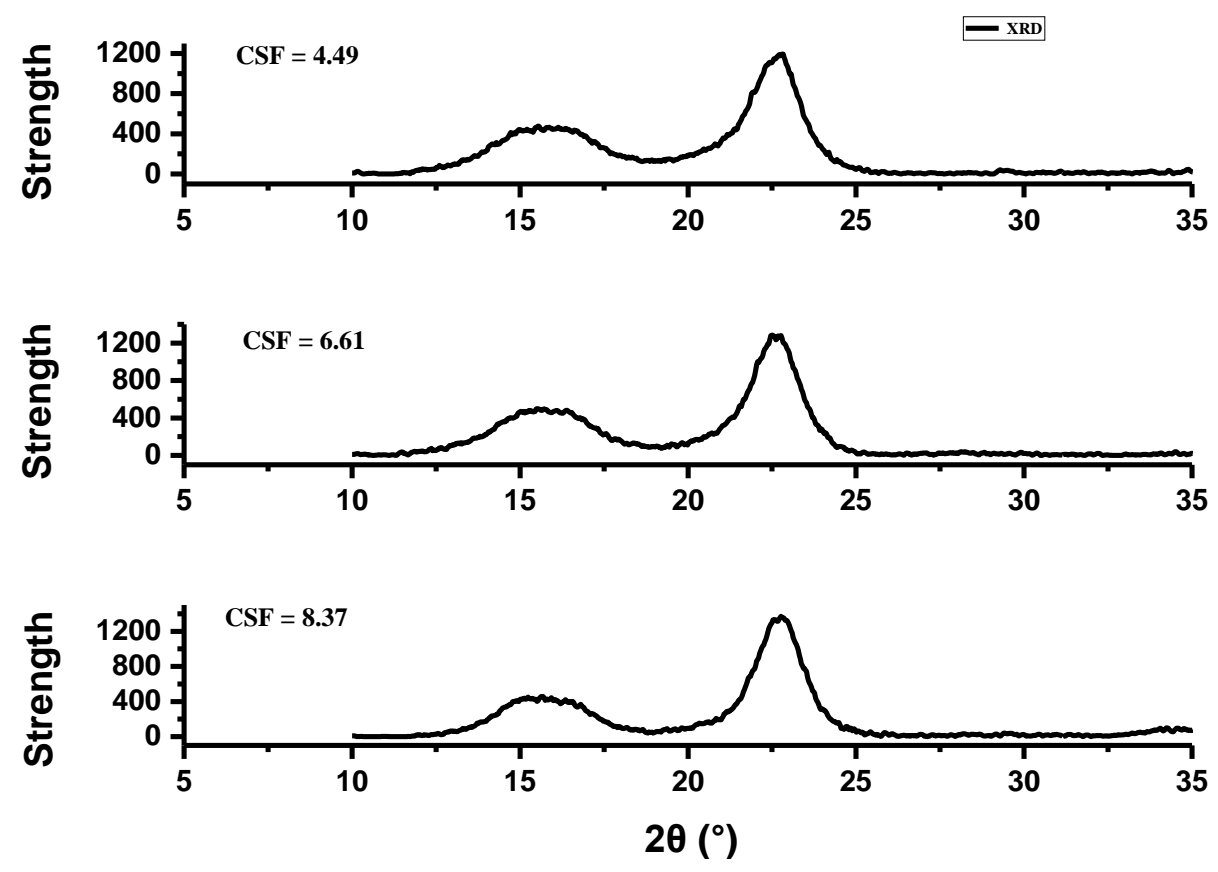

Fig. 4. XRD patterns of pulp samples from wood chips prehydrolyzed with different CSF values

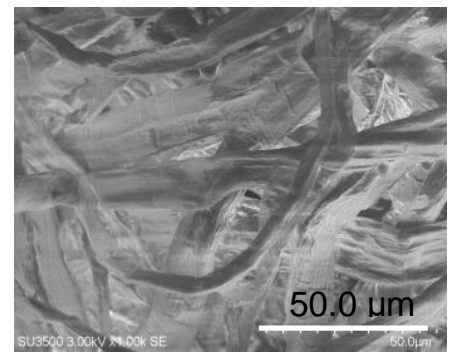

CSF $=4.37$

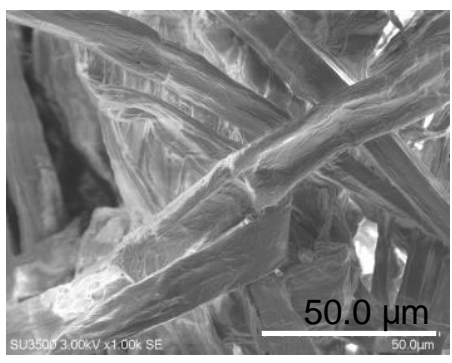

$\mathrm{CSF}=6.61$

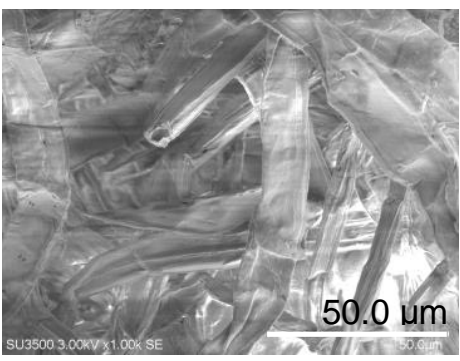

CSF $=8.37$

Fig. 5. SEM micrographs of pulp samples from wood chips prehydrolyzed with different CSF values 
Figure 5 shows the SEM micrographs of the fibers obtained from the different CSF values. It can be seen that fiber damage became more obvious as the CSF value increased. At a CSF value of 4.37, the fiber surfaces were slightly wrinkled. When the CSF was at 6.61, the surfaces of the fibers appeared damaged and fibrillated. At a CSF value of 8.37, the surfaces of the fibers were severely damaged with observable fiber fragments.

\section{CONCLUSIONS}

1. Prehydrolysis had a favorable influence on the kraft pulping and bleaching of the wood chips. A critical 5.81 CSF cut-off value was determined for prehydrolysis. When the CSF was higher than 5.81, the removal extents of the hemicelluloses and lignin were appreciably increased along with the pulp performance. The size of the pulp fibers tended to be stable and the surfaces of the fibers were damaged.

2. Under the optimum prehydrolysis (i.e., CSF of 6.61) of the wood chips and subsequent kraft pulping and $\mathrm{D}(\mathrm{EP}) \mathrm{P}$ bleaching, the brightness of the pulp was $85 \%$ ISO, the cellulose DP was 930, and the $\alpha$-cellulose content was 92.3\%; also, the pulp's Kappa number was 0.62 , and cellulose crystallinity was $75.4 \%$. This study provided an effective and reliable theoretical basis for the preparation of dissolving pulps by LHW prehydrolysis.

\section{ACKNOWLEDGMENTS}

The authors would like to express their thanks for the financial support from the National Key R\&D Program of China (Grant No. 2017YFB0307900), the National Natural Science Foundation of China (Grant Nos. 31670590, 31870566, and 31670595), the Shandong Key Research and Development Program (Grant Nos. 2018YFJH0401 and 2018GGX108001), Outstanding Youth Innovation Team Project of Shandong Provincial University (2019KJC014), the Taishan Scholars Program, and the Yuandu Leading Talents Program.

\section{REFERENCES CITED}

Agarwal, U. P., Ralph, S. A., Baez, C., Reiner, R. S., and Verrill, S. P. (2017). "Effect of sample moisture content on XRD-estimated cellulose crystallinity index and crystallite size," Cellulose 24(5), 1971-1984. DOI: 10.1007/s10570-017-1259-0

Al-Dajani, W. W., Tschirner, U. W., and Jensen, T. (2009). "Pre-extraction of hemicelluloses and subsequent kraft pulping Part II: Acid and autohydrolysis," TAPPI Journal 8(9), 30-37.

Borrega, M., Tolonen, L. K., Bardot, F., Testova, L., and Sixta, H. (2013). "Potential of hot water extraction of birch wood to produce high-purity dissolving pulp after alkaline pulping," Bioresource Technology 135, 665-671. DOI:

10.1016/j.biortech.2012.11.107 
Chum, H. L., Johnson, D. K., Black, S. K., and Overend, R. P. (1990). "Pretreatmentcatalyst effects and the combined severity parameter," Applied Biochemistry and Biotechnology 24-25, 1-14. DOI: 10.1007/BF02920229

Duarte, G. V., Ramarao, B. V., Amidon, T. E., and Ferreira, P. T. (2011). "Effect of hot water extraction on hardwood kraft pulp fibers (Acer saccharum, sugar maple)," Industrial \& Engineering Chemistry Research 50(17), 9949-9959. DOI: 10.1021/ie200639u

Francis, R. C., Hanna, R. B., Shin, S.-J., Brown, A. F., and Riemenschneider, D. E. (2006). "Papermaking characteristics of three Populus clones grown in the northcentral United States," Biomass and Bioenergy 30(8-9), 803-808. DOI: 10.1016/j.biombioe.2005.08.003

Overend, R. P., and Chornet, E. (1987). "Fractionation of lignocellulosics by steamaqueous pretrements: Discussion," Philosophical Transactions of the Royal Society A: Mathematical Physical \& Engineering Sciences 321(1561), 523-536. DOI: 10.1098/rsta.1987.0029

Gütsch, J. S., Nousiainen, T., and Sixta, H. (2012). "Comparative evaluation of autohydrolysis and acid-catalyzed hydrolysis of Eucalyptus globulus wood," Bioresource Technology 109, 77-85. DOI: 10.1016/j.biortech.2012.01.018

Hinck, J. F., Casebier, R. L., and Hamilton, J. K. (1985). "Dissolving pulp manufacture," in: Pulp and Paper Manufacture: Vol. 4 Sulfite Science and Technology, O. V. Ingruber, M. J. Kocurek, and A. Wong (eds.), The Joint Textbook Committee of the Paper Industry, Montréal, PQ, Canada, pp. 213-243.

Jahan, M. S., Rahman, M. M., and Sarkar, M. (2016). "Upgrading old corrugated cardboard (OCC) to dissolving pulp," Cellulose 23(3), 1-9. DOI: 10.1007/s10570016-0894-1

Le, H., Sixta, H., and Hummel, M. (2019). "Ionic liquids and gamma-valerolactone as case studies for green solvents in the deconstruction and refining of biomass," Current Opinion in Green and Sustainable Chemistry 18, 20-24. DOI: 10.1016/j.cogsc.2018.11.009

Leppänen, K., Spetz, P., Pranovich, A., Hartonen, K., Kitunen, V., and Ilvesniemi, H. (2011). "Pressurized hot water extraction of Norway spruce hemicelluloses using a flow-through system," Wood Science and Technology 45(2), 223-236. DOI: $10.1007 / \mathrm{s} 00226-010-0320-\mathrm{z}$

Li, M., Cao, S., Meng, X., Studer, M., Wyman, C. E., Ragauskas, A. J., and Pu, Y. (2017). "The effect of liquid hot water pretreatment on the chemical-structural alteration and the reduced recalcitrance in poplar," Biotechnology for Biofuels 10(1), Article No. 237, 1-13. DOI: 10.1186/s13068-017-0926-6

Lin, X., Wu, Z., Zhang, C., Liu, S., and Nie, S. (2018). "Enzymatic pulping of lignocellulosic biomass," Industrial Crops and Products 120, 16-24. DOI: 10.1016/j.indcrop.2018.04.033

Liu, J., Li, M., Luo, X., Chen, L., and Huang, L. (2015). "Effect of hot-water extraction (HWE) severity on bleached pulp based on biorefinery performance of eucalyptus during the HWE-kraft-ECF bleaching process," Bioresource Technology 181, 183190. DOI: 10.1016/j.biortech.2015.01.055.

Narron, R. H., Chang, H.-M., Jameel, H., and Park, S. (2017). "Soluble lignin recovered from biorefinery pretreatment hydrolysate characterized by lignin-carbohydrate complexes," ACS Sustainable Chemistry \& Engineering 5(11), 10763-10771. DOI: 10.1021/acssuschemeng.7b02716 
Oliveira, S. D., De Araújo Padilha, C. E., Asevedo, E. A., Pimentel, V. C., De Araújo, F. R., De Macedo, G. R., and Dos Santos, E. S. (2017). "Utilization of agroindustrial residues for producing cellulases by Aspergillus fumigatus on semi-solid fermentation," Journal of Environmental Chemical Engineering 6(1), 937-944. DOI: 10.1016/j.jece.2017.12.038

Pedersen, M., and Meyer, A. S. (2010). "Lignocellulose pretreatment severity - relating pH to biomatrix opening," New Biotechnology 27(6), 739-750. DOI: 10.1016/j.nbt.2010.05.003

Rizaluddin, A. T., Liu, Q., Panggabean, P. R., Ohi, H., and Nakamata, K. (2015). "Application of peroxymonosulfuric acid as a modification of the totally chlorine-free bleaching of acacia wood prehydrolysis-kraft pulp," Journal of Wood Science 61(3), 292-298. DOI: 10.1007/s10086-015-1465-z

Sixta, H. (2006). Handbook of Pulp, Wiley-Verlag GmbH \& Co., Weinheim, Germany.

Sluiter, A., Hames, B., Ruiz, R., Scarlata, C., Sluitter, J., Templeton, D., and Crocker, D. (2012). Determination of Structural Carbohydrates and Lignin in Biomass (Technical Report NREL/TP-510-42618), National Renewable Energy Laboratory, Golden, CO, USA.

Shi, S.-L., He, F.-W., Zhang, Z., and Yang, R.-N. (2015). Pulp and Paper Analysis and Testing, China Light Industry Press, pp. 65-73.

Shi, H., Zhou, M., Li, C., Sheng, X., Yang, Q., Li, N., and Niu, M. (2019). "Surface sediments formation during auto-hydrolysis and its effects on the benzene-alcohol extractive, absorbability and chemical pulping properties of hydrolyzed acacia wood chips," Bioresour Technol. 289. DOI:10.1016/j.biortech.2019.121604

TAPPI T203 cm-09 (2009). “Alpha-, beta- and gamma-cellulose in pulp,” TAPPI Press, Atlanta, GA, USA.

TAPPI T230 om-13 (2013). "Viscosity of pulp (capillary viscometer method)," TAPPI Press, Atlanta, GA, USA.

TAPPI T236 om-06 (2006). "Kappa number of pulp,” TAPPI Press, Atlanta, GA, USA.

TAPPI T452 om-92 (1992). "Brightness of pulp, paper, and paperboard (directional reflectance at $457 \mathrm{~nm}$ )," TAPPI Press, Atlanta, GA, USA.

Teleman, A., Larsson, P. T., and Iversen, T. (2001). "On the accessibility and structure of xylan in birch kraft pulp," Cellulose 8(3), 209-215. DOI: 10.1023/A:1013195030404

Walton, S. L., Hutto, D., Genco, J. M., Van Walsum, G. P., and Van Heiningen, A. R. P. (2010). "Pre-extraction of hemicelluloses from hardwood chips using an alkaline wood pulping solution followed by kraft pulping of the extracted wood chips," Industrial \& Engineering Chemistry Research 49(24), 12638-12645. DOI: 10.1021/ie100848p

Wang, Z., Wang, X., Jiang, J., Fu, Y., and Qin, M. (2015). "Fractionation and characterization of saccharides and lignin components in wood prehydrolysis liquor from dissolving pulp production," Carbohydrate Polymers 126, 185-191. DOI: 10.1016/j.carbpol.2015.03.012

Weinwurm, F., Turk, T., Denner, J., Whitmore, K., and Friedl, A. (2017). “Combined liquid hot water and ethanol organosolv treatment of wheat straw for extraction and reaction modeling," Journal of Cleaner Production 165, 1473-1484. DOI: 10.1016/j.jclepro.2017.06.215

Yang, P., Kobayashi, H., and Fukuoka, A. (2011). "Recent developments in the catalytic conversion of cellulose into valuable chemicals," Chinese Journal of Catalysis 32(5), 716-722. DOI: 10.1016/s1872-2067(10)60232-x 
Yao, S., Ni, S., Zhu, H., Wang, S., Song, X., and Qin, C. (2017). "Extraction of hemicellulose by hot water to reduce absorbable organic halogen formation in chlorine dioxide bleaching of bagasse pulp," Industrial Crops and Products 96, 178185. DOI: $10.1016 /$ j.indcrop.2016.11.046

Yuan, S., Ji, X., Ji, H., Tian, Z., and Chen, J. (2019). “An optimum combined severity factor improves both the enzymatic saccharification yield and the functional lignin structure," Cellulose 26(8), 4731-4742. DOI: 10.1007/s10570-019-02442-9

Zhang, H., Qin, C., Nie, S., and Wang, S. (2018). "Effects of D-hot pretreatment on micro-distribution of residual lignin in sugarcane bagasse pulp and fiber properties," Cellulose 25(8), 4423-4435. DOI: 10.1007/s10570-018-1883-3

Article submitted: November 7, 2019; Peer review completed: January 23, 2020; Revised version received: February 2, 2020; Accepted: February 3, 2020; Published: April 20, 2020. DOI: $10.15376 /$ biores.15.2.4323-4336 